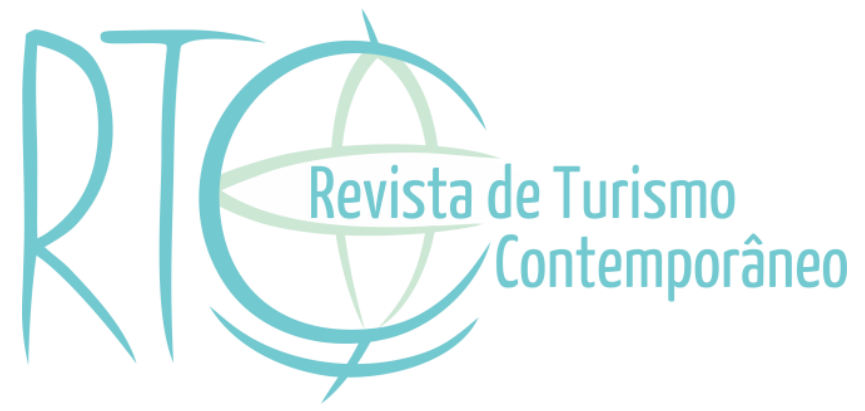

\title{
A qualidade de serviços em atrativos turísticos de Florianópolis à luz da teoria do turismo de experiência
} The services quality on tourism attractions of Florianópolis in the light of experience tourism theory

\section{Tiago Savi Mondo}

Professor do Instituto Federal de Santa Catarina -IFSC, Florianópolis /SC, Brasil.

E-mail: tiago.mondo@ifsc.edu.br

\section{Mariana Carla Talini}

Tecnóloga em Hotelaria pelo Instituto Federal de Santa Catarina-IFSC, Florianópolis/SC, Brasil.

E-mail: mariana.talini@hotmail.com

\section{Gabriela Gonçalves Silveira Fiates}

Professora de Administração da Universidade Federal de Santa Catarina-UFSC, Florianópolis/SC, Brasil.

E-mail: gabriela.fiates@ufsc.br 


\section{RESUMO}

A experiência que o turista tem no destino começou a ser estudada com maior ênfase na última década. Ao considerar que a percepção de qualidade do serviço turístico por parte do turista leva em conta sua experiência no destino, esta pesquisa objetiva analisar esta relação (qualidade percebida $\mathrm{x}$ experiência) a partir da percepção de turistas de Florianópolis. $\mathrm{O}$ estudo é caracterizado como quantitativo, descritivo e do tipo estudo de campo. O instrumento utilizado para a coleta de dados foi o questionário, baseado no modelo TOURQUAL, criado e validado por Mondo (2014). A amostra do estudo é considerada probabilística e compreendeu 476 turistas de Florianópolis. Os principais resultados indicam que, com relação a importância do indicador para a qualidade, estética (beleza) e evasão (fuga da rotina) aparecem a frente de entretenimento e aprendizado. $\mathrm{Na}$ real avaliação da qualidade, os turistas indicaram que Estética, evasão e aprendizado são indicadores que estão em um nível de bom a excelente nos atrativos de Florianópolis, enquanto o Aprendizado está em um nível de mediano a bom.

Palavras-chave: Turismo de Experiência. Qualidade de Serviços. TOURQUAL. Florianópolis.

\section{ABSTRACT}

The experience in the tourist destination has begun to be studied with greater emphasis in the last decade. Pine and Gilmore are the pioneering authors in this area. When considering that the perception of quality of tourist service by the tourist takes into account your experience in the destination, this research aims to analyze this relationship (perceived quality experience $\mathrm{x}$ ) from the perception of tourists from Florianópolis. The study is characterized as quantitative, descriptive study and the type of field. The instrument used for data collection was a questionnaire based on TOURQUAL model, created and validated by Mondo (2014). The study sample is considered probabilistic and understood 476 tourists from Florianópolis. The main results indicate that, compared with the importance of the indicator for the quality, aesthetics (beauty) and avoidance (escape from routine) appear in front of entertainment and learning. In real quality assessment indicated that tourists Aesthetics, dropout and learning are indicators that are on a level of good to excellent attractions in Florianopolis, while the learning is at a level of medium to good.

Keywords: Tourism Experience. Quality of Services. TOURQUAL.Florianópolis. 


\section{INTRODUÇÃO}

O Turismo surgiu como um fenômeno global na década de 1960. Naqueles primeiros anos, foi incontestável o potencial para gerar desenvolvimento econômico. Governos nacionais olharam para o turismo como gerador de renda, como um meio de gerar divisas, como fonte de emprego, e como um meio de trazer maiores benefícios econômicos para as regiões com limitado potencial. (ONU, 1999).

O turismo serve um grande número de viajantes e abrange diversas atividades tais como transporte, alojamento, entretenimento, alimentação e restauração. Ele precisa de uma abordagem global, a fim de alcançar o desenvolvimento sustentável. A necessidade de benefícios de curto prazo e ativos duráveis justifica a maior integração e harmonização do turismo com outras atividades e serviços relacionados, de modo a beneficiar as comunidades de acolhida. Atividades e serviços complementares e relacionados, dependendo do tipo de turismo, devem ser levados em conta ou planejados em conjunto para torná-los mais produtivos, promover desenvolvimento auto-sustentado, fornecer a infra-estrutura e os serviços necessários, e garantir o respeito pela natureza e cultura (ONU, 1994)

No Brasil o turismo representa uma das principais atividades econômicas do setor de serviços, segundo o Instituto Brasileiro de Geografia e Estatística [IBGE] (2013). De acordo com a Organização Mundial de Turismo [OMT] (2012), o turismo gerou mais de 1 trilhão de dólares em 2012, com crescimento de 3\% em relação a 2011. No Brasil, este número chega a 28 bilhões de reais, calculando-se somente o turismo internacional (IBGE, 2013).

Assim, o turismo desempenha papel fundamental na vida das pessoas, seja por motivos de lazer e descanso, seja por motivos profissionais. Porém, uma questão pouco abordada na área do turismo e do marketing empresarial é como as características da oferta de serviços se refletem na percepção e vivência da experiência turística. Entender como tal processo funciona abre uma lacuna para análises novas, a partir de temas já bem conhecidos.

Os serviços turísticos possuem qualidade em escala - isto é, a performance de um afeta a percepção do todo por estarem todos interligados à mesma marca do destino (Buhalis, 1999).

Em termos de posicionamento competitivo, Pine e Gilmore (1998) propõem a análise da Progressão de Valor Econômico da Experiência, um modelo evolutivo cujas variáveis são o aumento de diferenciação, relevância e preço. Partem então da divisão tradicional das 
atividades de mercado em Commodities, Bens de Consumo e Serviços e acrescentam a Experiência como composta por uma ainda mais alta capacidade de diferenciação e grau de relevância para o cliente a preço premium.

A partir deste turismo moderno, alguns modelos de qualidade em serviços foram criados para determinados equipamentos turísticos, ou seja, para determinados tipos de prestação de serviços. Porém, estes ainda são pouco utilizados, como o HOTELQUAL de Sierra et. al (1999) para meios de hospedagem, o DINESERV de Knutson, Stevens e Patton. (1996) para restaurantes e o HISTOQUAL de Frochot e Hughes (2001) para museus e castelos.

O modelo utilizado nesta pesquisa foi o desenvolvido por Mondo (2014), denominado TOURQUAL, específico para avaliação da qualidade de serviços em atrativos turísticos em que uma de suas categorias de análise é a experiência vivenciada pelo turista no atrativo.

Estudar a experiência no turismo é compreender como a mente do turista se comporta ao visitar um local, ao trazer toda a sua carga cultural, emocional, suas expectativas e, inconscientemente, compará-las a este novo lugar. É uma nova visão de estudo da qualidade no turismo, pois cada turista vem de um local diferente, com renda e graus de escolaridade distintos, o que irá influenciar em sua expectativa que mudará completamente sua forma de ver o destino visitado.

No século XXI, onde o consumidor quer ser tratado com exclusividade, reconhecer o turismo de experiência pode ser um fator relevante para o crescimento dos negócios e um grande diferencial competitivo. O turista espera que o destino proporcione sensações não disponíveis em nenhuma outra opção. Segundo Pine e Gilmore (1999), os negócios que entenderem esta nova relação com o cliente se protegerão das forças de commoditização, criando, portanto, um novo valor econômico.

Dessa forma, aliar a percepção do turista com sua experiência no atrativo e a percepção de qualidade dos serviços do atrativo torna-se possível e julga-se relevante à gestores e pesquisadores da área.

O local deste estudo foi Florianópolis, por ser reconhecidamente um destino turístico brasileiro e por proximidade dos pesquisadores. Dessa forma, chega-se ao problema de pesquisa: qual a percepção de turistas com relação à experiência vivenciada em atrativos

turísticos de Florianópolis? Para respondê-la, desenvolveu-se o objetivo geral da pesquisa: Verificar a percepção da experiência vivenciada em serviços nos atrativos turísticos de Florianópolis, a partir do modelo TOURQUAL. 
Além desta introdução, este artigo está subdivido em mais 4 seções. A seguir, são apresentados os principais fundamentos teóricos que embasaram este artigo, seguido pelo tópico de procedimentos metodológicos, resultados e considerações finais.

\section{FUNDAMENTAÇÃO TEÓRICA}

\subsection{QUALIDADE DE SERVIÇOS}

O setor de serviços está passando por uma mudança quase revolucionária, afetando drasticamente o modo como as pessoas vivem e trabalham, uma vez que, continuamente, novos serviços são lançados para satisfazer as necessidades existentes e, também, aquelas que sequer são percebidas pelos consumidores (Lovelock, 2006). Neste cenário, compreender o comportamento do consumidor se torna chave para se conseguir mantê-los, em especial no setor de serviços que é, essencialmente, intangível (Kotler, 2000).

Uma das teorias mais consolidadas na área de qualidade de serviços é a chamada PZB, em referência aos seus criadores (Parasuraman, Berry \& Zeithaml, 1985). Nesta teoria, as dimensões da qualidade nos serviços foram identificadas a partir de 10 itens, considerados os determinantes da qualidade. Esses elementos são percebidos pelos clientes e confrontados com suas expectativas. Estes autores explicam que a acessibilidade indica o fácil acesso de contato (localização, horários, comunicação); já a comunicação está relacionada com manter os clientes informados sobre os serviços, numa linguagem que eles possam entender; a competência está relacionada com as habilidades necessárias para prestar o serviço; cortesia envolve tratar os clientes com respeito, educação, consideração e cordialidade; e a credibilidade implica ser confiável e honesto. A confiabilidade de um serviço envolve cumprir com o que foi prometido, nos termos em que foi prometido; já a presteza compreende a demonstração de vontade em prestar o serviço; a segurança refere-se à tentativa de livrar os clientes de perigos, riscos ou dúvidas nos âmbitos: físico, financeiro e confidencial; os aspectos tangíveis são representados pela evidência física do serviço; e o conhecimento do cliente implica nos esforços para compreender as necessidades dos clientes.

Mais tarde, Parasuraman, Zeithaml e Berry (1988) reduziram para cinco os elementos de satisfação em serviços: permanecendo a confiabilidade, a responsividade, a segurança, a empatia e os aspectos tangíveis. 
Para entender o comportamento da demanda existente e poder atendê-la, é necessário o uso de técnicas que possam avaliar a qualidade do serviço que é percebida pelos consumidores. Uma ferramenta que possibilita mensurar essa qualidade é a escala SERVQUAL, um questionário criado a partir da teoria PZB (Parasuraman, Zeithaml \& Berry, 1985). A função deste questionário é medir as expectativas e as percepções dos clientes por um serviço de qualidade.

Essa ferramenta tem sido severamente criticada principalmente por dois motivos. $\mathrm{O}$ primeiro relaciona-se à crença de que a mensuração da qualidade percebida por si só já explicaria o desempenho do fornecedor de serviços e também a satisfação do consumidor, tornando desnecessária a mensuração da expectativa de desempenho (Cronin \& Taylor, 1992). O segundo refere-se ao entendimento de que os atributos mensurados pela escala são do tipo vetorial, isto é, na expectativa do consumidor, o atributo em sua plenitude tenderia ao infinito (Teas, 1994). No entanto, apesar das críticas a SERVQUAL ainda é tida como a mais tradicional ferramenta para a mensuração da qualidade de serviço percebida (Hughey, Chawla \& Khan, 2003), já tendo sido replicada muitas vezes, em diversas ocasiões, no cenário varejista nacional e no internacional. Outras críticas foram feitas ao SERVQUAL por estar preocupado com a solidez psicométrica e metodológica de escalas, por ser utilizado e testado apenas em países desenvolvidos, e por ter as medidas do modelo estáticas, na medida em que não consideram a história do serviço e não consegue captar a dinâmica da expectativa de mudança (Jayasundra, Ngulube, \& Minishi-Majanja 2009).

Entende-se deste modo, que existem algumas divergências com relação à mensuração da qualidade de serviços e os modelos/métodos/ferramentas utilizados para tal. Acreditando que este é um tema que merece maior atenção de estudos científicos, Mondo (2014) desenvolveu um modelo/protocolo específico para avaliar a qualidade de serviços em atrativos turísticos, tema central desta pesquisa.

\subsection{O MODELO TOURQUAL}

De acordo com Mondo (2014), o TOURQUAL é um modelo teórico e um protocolo de avaliação da qualidade de serviços em atrativos turísticos. Para o seu desenvolvimento o pesquisador levantou os principais modelos de qualidade de serviços presentes na literatura, analisou mais de 65 mil comentários de turistas sobre atrativos no site tripadvisor.com e validou com amostra significativa o modelo. 
O TOURQUAL é formado por seis categorias, uma delas a utilizada neste estudo: a experiência. O diagrama do modelo é apresentado na Figura 1.

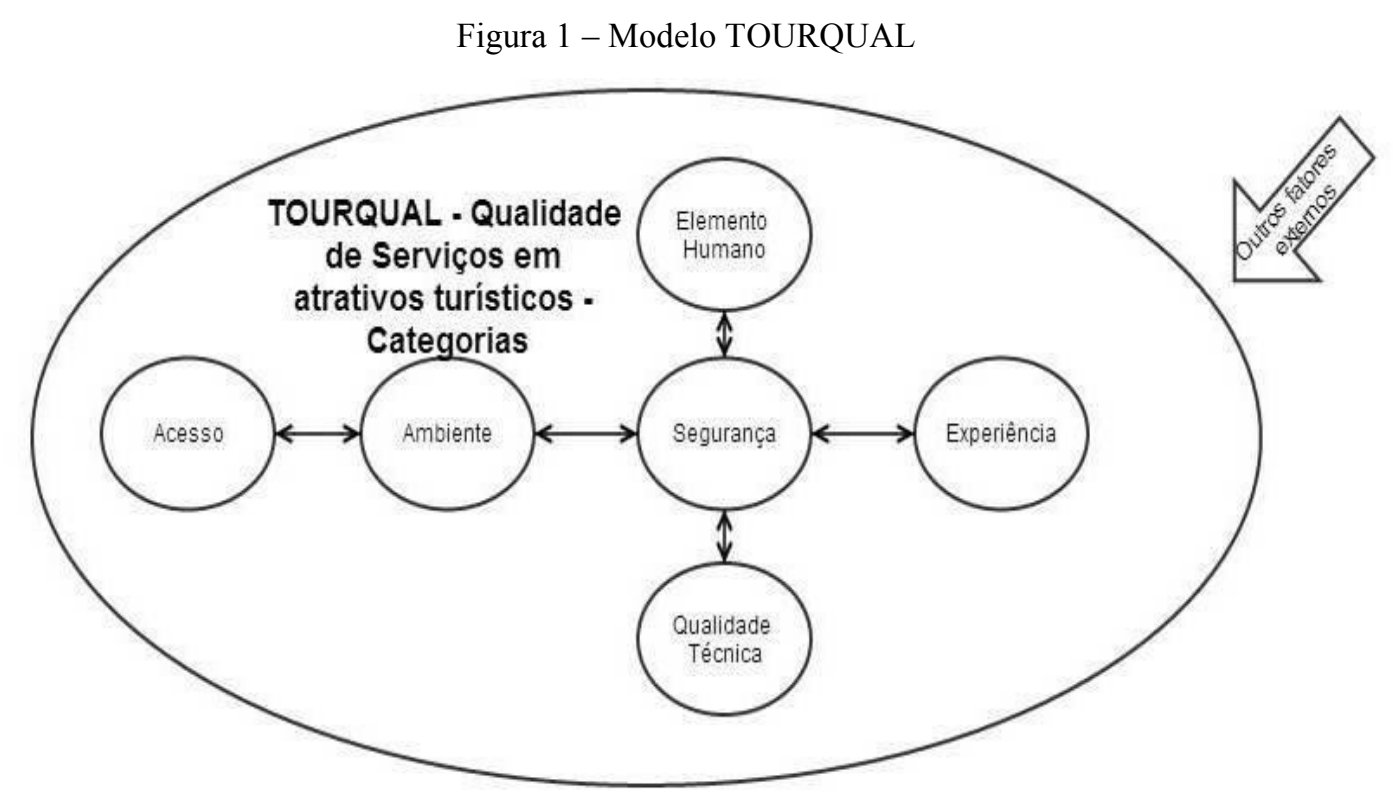

Fonte: Mondo (2014)

Cada uma das seis categorias do TOURQUAL possui indicadores de avaliação, que juntos, formam o protocolo. O quadro 1 apresenta os indicadores desenvolvidos por Mondo (2014). 


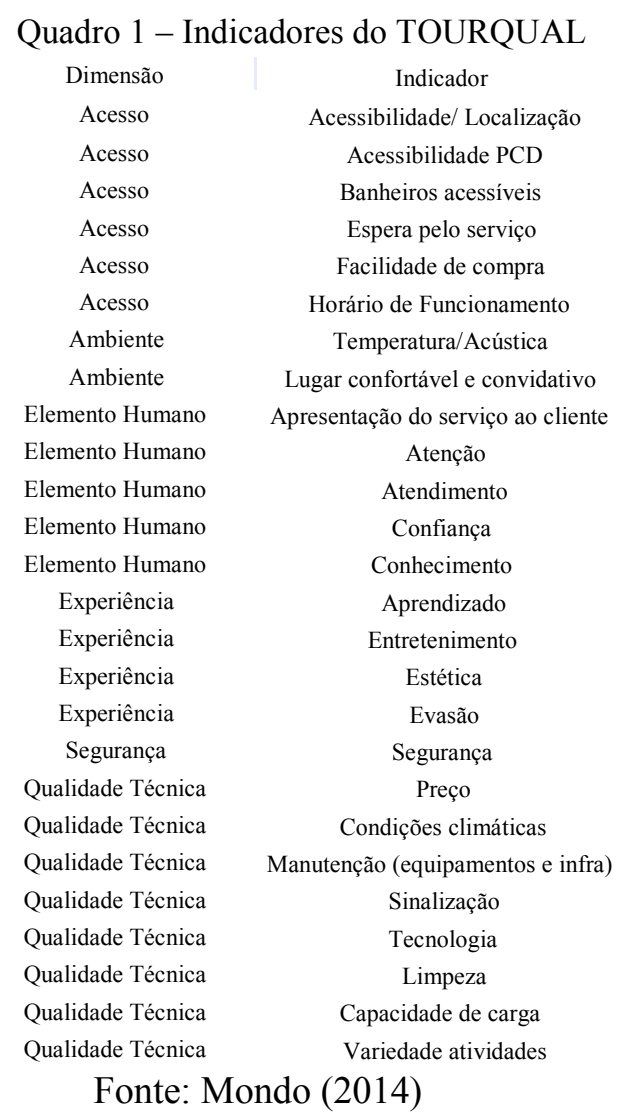

Esta pesquisa limita seus esforços na categoria de experiência, buscando identificar a percepção de qualidade dos serviços em atrativos turísticos de Florianópolis a partir dos indicadores de evasão, entretenimento, estética e aprendizado. Segundo Mondo (2014) esta categoria foi baseada nos estudos de Pine e Gilmore (1999).

\subsection{TURISMO DE EXPERIÊNCIA}

A experiência em serviços tem sido um tema bastante discutido na academia. Primeiro pelo caráter simultâneo dos serviços, onde provavelmente o cliente e o provedor estarão em contato e, segundo, pelo caráter intangível e heterogêneo do serviço e do encontro de serviço. Hume (2011) afirma que o "encontro de serviço" ou "experiência de serviço" é toda a transação recebida pelo cliente.

O pioneiro da economia de experiência é Walt Disney. Enquanto as ofertas econômicas anteriores são externas ao comprador, as experiências são intrinsecamente pessoais e só existem na mente da pessoa que tenha sido cativada em um nível emocional, físico, intelectual ou até mesmo espiritual. Assim, duas pessoas não podem ter a mesma 
experiência, porque cada experiência deriva da interação entre o acontecimento organizado (como uma peça teatral) e o humor da pessoa. (Beni, 2004)

Beni (2004) aponta a inclinação do mercado para uma nova proposta de marketing que surgiu em 1997 quando pesquisadores e autores ressaltam uma mudança de foco passando a destacar os benefícios das experiências proporcionadas por uma empresa ou por uma marca como um todo, e o planejamento estético que é essencial ao desenvolvimento e implementação de uma marca ou identidade empresarial. As experiências compreendem: sabor, odor, visão, tato, cor, som, entre outros. Uma experiência não é uma construção informe; é uma oferta tão real quanto qualquer serviço, produto ou mercadoria.

$\mathrm{Na}$ categoria de experiência, a partir da literatura específica, foram elaborados quatro indicadores de análise (Entretenimento, Evasão, Estética e Aprendizado) conforme preconizado por Pine e Gilmore (1998). Após as análises, verificou-se que todos os indicadores foram aderentes aos comentários dos turistas.

Pine e Gilmore (1999) ao definir a economia da experiência, produziram quatro dimensões as quais o consumidor/turista pode vivenciar. A partir disso, essas dimensões são aqui caracterizadas como elementos da qualidade de serviços, visto que o turista é parte integrante do processo e vivencia emoções e experiência nas suas viagens.

Aprendizado: $O$ indicador de aprendizado diz respeito ao quanto o turista aprendeu em determinado atrativo. Muitos turistas não buscam o aprendizado em suas viagens, entretanto, acabam aprendendo em um guiamento ou na leitura de alguma placa indicativa.

Promover o aprendizado ao turista é uma forma de oferecer um serviço com qualidade. De acordo com Pine e Gilmore (1998), a aprendizagem ocorre quando há participação ativa, pois o envolvido precisa absorver o que é ensinado. Nesse contexto, o responsável pela atividade deve saber exatamente aquilo que deseja ensinar ao participante.

Entretenimento: O entretenimento, de acordo com Pine e Gilmore (1998), tem participação passiva e conexão direta com o ambiente e refere-se à reação dos indivíduos em relação aos elementos que são a eles disponibilizados, utilizando os cinco sentidos, proporcionando satisfação, riso ou relaxamento. Desenvolver essa dimensão significa potencializar a absorção positiva da experiência proporcionada a fim de torná-la mais atrativa e memorável para o cliente.

Evasão: Envolve a participação ativa relacionada à imersão ao ambiente. Nessa dimensão, quem propor a atividade tem a responsabilidade de manter o consumidor imerso a ela, prendendo a sua atenção (Pine \& Gilmore, 1998). Ao trazer à realidade do questionário, a evasão diz respeito as atividades que não são rotineiras dos turistas. 
Estética: De acordo com Tuan (1980, p. 74), “a avaliação do meio ambiente pelo visitante é essencialmente estética. É a visão de um estranho. O estranho julga pela aparência, por algum critério formal de beleza". E este é um aspecto que pode ser observado em atrativos turísticos, pois a imagem para visitante é a do momento, ele está ali de passagem, é a fotografia do local, é estético.

Pine II e Gilmore (1999) ainda defendem que na esfera da contemplação ou estética há uma imersão mais contemplativa, passiva, ou seja, o indivíduo aprecia o espaço de uma maneira mais visual. Assim, a estética é o que faz com que os visitantes queiram entrar e ficar no local, eles o capturam como acolhedor, interessante ou confortável. Consideramos como estética a beleza dos atrativos turísticos.

Nas pesquisas acadêmicas brasileiras, muito tem se pesquisado sobre turismo de experiência. Esse movimento é benéfico à academia e dá base para novos estudos com perspectivas diferenciadas, como a proposta aqui exposta. Por exemplo, Akel, Gândara e Brea (2012) realizaram uma pesquisa comparativa para verificar qual o melhor modelo de métricas da experiência em restaurantes e bares. Ao analisarem o SERVQUAL, o DINESERV e o Modelo da Qualidade da Experiência Gimenes, Brea, e Gândara (2012) identificaram que os três se complementam, mas que o de Gimenes et. al. (2012) é mais específico e abrange melhores métricas para o setor.

Pulido-Fernandez e Hermoso (2014) também pesquisaram itens para mensuração da experiência do turista no destino, onde levaram em conta as dimensões de Pine e Gilmore e aprofundaram-nas, criando um arcabouço de indicadores para cada dimensão.

Barbosa e Farias (2012) buscaram identificar junto a consumidores de restaurantes o que seriam experiências ordinárias (utilitárias) e hediônicas (extraordinárias) e como essa interação influencia na formação da percepção da experiência.

Nascimento, Maia e Dias (2012) realizaram um estudo teórico levantando a importância da experiência na criação de emoções e vivências diferenciadas para os turistas. Horodyski, Manosso e Gândara (2012), identificaram as percepções da experiência de turistas que consumiram souveniers em Curitiba-PR, mostrando que a busca pelo turismo de experiência pode ser realizada em diferentes facetas do processo turístico.

Outros estudos tiveram como foco de pesquisa a experiência do turista, como o de Silva e Santos (2011) que buscou identificar as experiências dos visitantes no Museu do Futebol, o de Tonini e Lavandoski (2011) que objetivou identificar as experiências dos enoturistas no Vale dos Vinhedos-RS. 
Gomes, Salazar e Leite (2013) pesquisaram os atributos estéticos de dois casos de hotelaria de luxo e como influenciam a percepção de experiência dos hóspedes. Ainda na hotelaria, Ladeira, Santini e Costa (2013) buscaram relacionar a experiência do consumo com os antecedentes do consumo e a satisfação do hóspede, obtendo relação positiva. Barbosa, Souza, Kovacs e Melo (2011) também pesquisaram experiências ordinárias e extraordinárias na hotelaria. Mondo (2010) estudou o caso de um Resort em Santa Catarina e como este trabalhava a experiência com os hóspedes. Outro estudo, de Mondo e Costa (2010), teve um foco diferente dos demais ao pesquisar as experiência oferecidas pelos meios de hospedagem aos agentes de viagens por meio dos fam-tours.

Percebe-se assim, que muitos estudos tem sido feitos levando-se em consideração a experiência no turismo. Alguns teóricos, outros de campo. Este estudo vem justamente para complementar os demais, a partir de uma nova perspectiva de avaliação exclusiva de atrativos turísticos, sendo esta sua contribuição à área.

\section{PROCEDIMENTOS METODOLÓGICOS}

\subsection{NATUREZA DE PESQUISA}

No que tange a filosofia de pesquisa, caracteriza-se como positivista. Collis e Hussey (2005) mencionam que a pesquisa positivista é projetada para obter informações sobre variáveis em diferentes contextos, mas simultaneamente. Quanto à abordagem do problema esta pesquisa caracteriza-se por ser quantitativa que é denominada também de pesquisa de levantamento (Creswell, 2007). Tem por característica principal a descrição quantitativa ou numérica de tendências, atitudes ou opiniões de uma população. Assim, se enquadra no objetivo deste estudo.

Com relação ao espectro temporal, essa pesquisa caracteriza-se por ser transversal. Os dados foram coletados apenas uma vez, em um período de tempo curto, antes de serem analisados e relatados. É um instantâneo de uma situação em andamento. Quanto aos objetivos, é caracterizada como uma pesquisa exploratória-descritiva. 


\subsection{UNIVERSO DE AMOSTRA}

Foi considerado como universo desta pesquisa, todos os turistas que consumiram atrativos turísticos de Florianópolis, caracterizando-se como um universo infinito.

A amostra é do tipo probabilística que, conforme Gil (2002), é aquela que é rigorosamente científica e baseada nos princípios fundamentais da estatística. Os métodos de amostragem probabilística são os que selecionam os indivíduos da população de forma que todos tenham as mesmas chances de participar da amostra.

A técnica de seleção da amostra junto ao universo será a de amostragem probabilística simples, ou seja, "[...] caracteriza-se pelo fato de cada elemento da população ter probabilidade conhecida, diferente de zero, idêntica à dos outros elementos, de ser selecionado para fazer parte da amostra." (Mattar, 1996, pg. 275).

A partir do cálculo para amostra infinita de Malhotra (2006), para nível de confiança de $95 \%$ e erro amostral de 5\%, a meta amostral desta avaliação foi de 400 turistas, entretanto a amostra do estudo foi de 476 turistas, o que resultou em um erro amostral de 4,6\%.

\subsection{INSTRUMENTO DE PESQUISA}

A coleta de dados foi realizada mediante aplicação de questionário estruturado e não disfarçado junto a turistas visitando/consumindo os serviços de atrativos turísticos. O método de levantamento de dados para pesquisas de natureza quantitativa e descritiva envolve "[...] um questionário estruturado dado a uma amostra de uma população e destinado a provocar informações específicas dos entrevistados.” (Malhotra, 2006, p.179).

O questionário foi elaborado de maneira formal e com ordenamento de questões prédeterminadas. As perguntas foram dispostas de forma compactada, com um layout claro e agradável, evitando assim que o respondente encontrasse dificuldades quanto a sua extensão, entendimento ou subjetividade das questões. A forma de aplicação foi mediante entrevista pessoal com os turistas, realizado por pessoal treinado para esta atividade e em plataforma online.

O questionário buscou identificar duas questões principais com relação aos indicadores da qualidade: nível de percepção de qualidade do cliente e valor percebido, todos por meio de escala likert de cinco pontos. 


\subsection{PROCEDIMENTO DE COLETA E ANÁLISE DE DADOS}

A coleta de dados se deu em Florianópolis, nos meses de Fevereiro e Março de 2014. Dos questionários aplicados, 206 foram de maneira presencial com os turistas e 270 por meio de questionário online. Os dados foram tabulados e analisados com a utilização do software estatístico SPSS 17. Para análise dos dados foram utilizadas técnicas de estatística descritiva e nferencial/aplicada.

\section{RESULTADOS}

O questionário aplicado aos turistas da cidade de Florianópolis baseia-se em seis categorias consideradas fundamentais para avaliar a qualidade de serviços em atrativos turísticos. São elas: acesso, elemento humano, ambiente, segurança, experiência e qualidade técnica. Esta pesquisa levou em conta somente os dados da categoria de experiência (Mondo, 2014).

Com relação à caracterização da amostra de turistas percebe-se que quase metade dos respondentes (46\%) é de Santa Catarina. Tal fato está de acordo com a pesquisa de demanda da SANTUR (2013) que chegou no índice de 43,97\%, mesmo dado confirmado pela FECOMERCIO (2014) que pesquisou a demanda no período de Carnaval em Florianópolis, São Francisco do Sul, Laguna e Joaçaba e chegou nos índices perto dos 40\%.

O segundo Estado de origem dos turistas respondentes foi o Rio Grande do Sul (33,2\%) seguido pelo Paraná com 12,6\%. Percebe-se que a amostra possui $91,7 \%$ dos respondentes residentes da região Sul do Brasil, o que também corrobora em grande parte as pesquisas supracitadas.

A região Sudeste do país vem em seguida, com São Paulo (4,5\%), Rio de Janeiro $(1,1 \%)$ e Minas Gerais $(0,5 \%)$. A amostra também compreendeu respondentes dos estados da Bahia (0,5\%), Mato Grosso do Sul (0,5\%), Goiás (0,5\%), Mato Grosso (0,2\%) e Pará $(0,2 \%)$. Dessa forma, todas as regiões brasileiras foram representadas na amostra deste estudo.

Com relação ao gênero, a amostra se mostrou homogênea, tendo 51,4\% de mulheres e $48,6 \%$ de homens respondendo a pesquisa.

No quesito de estado civil, verificou-se que 155 respondentes eram casados $(49,2 \%)$, seguidos de 129 solteiros (41\%), 29 divorciados $(9,2 \%)$ e dois viúvos $(0,6 \%)$. Por último, a 
idade dos respondentes teve uma média de 34,21 anos, com 10,27 anos de desvio-padrão, o que resulta de $95 \%$ da amostra estar na faixa de 24 e 45 anos.

A primeira pergunta do questionário foi para selecionar um atrativo que o turista pudesse avaliar e dessa forma, embasar toda a sua percepção de qualidade da experiência. A partir da coleta de dados, verificou-se que 50,7\% dos respondentes escolheram uma praia de Florianópolis para avaliar.

Outro famoso atrativo em Florianópolis é a Lagoa da Conceição. Acrescenta-se a Barra da Lagoa, a Costa da Lagoa e o Canto da Lagoa, locais reconhecidos pela excelente oferta gastronômica e de lazer. Outras Lagoas são menos conhecidas dos turistas, entretanto também apareceram na amostra como a Lagoa do Peri. Todos os atrativos relacionados à Lagoas representaram $16,7 \%$ das escolhas dos turistas respondentes da pesquisa.

Em terceiro lugar na escolha de atrativos para avaliar, aparece o Centro Histórico de Florianópolis, onde foram identificados atrativos como a Praça XV de Novembro, o Mercado Público e as Construções Históricas, com 10,4\% da amostra total. Na quarta posição aparecem dois Bairros Históricos (Santo Antônio de Lisboa e Ribeirão da Ilha). A escolha deste atrativo representou $8,5 \%$ da amostra.

Percebe-se assim, que os atrativos escolhidos pelos turistas em sua maioria são naturais, atrativos construídos com e sem objetivo turístico tem menor representatividade e os eventos não apareceram na escolha, embora no período de coleta de dados tenha ocorrido um evento musical com repercussão nacional, o Planeta Atlântida e o Carnaval.

\subsection{AVALIAÇÃO DOS INDICADORES}

O primeiro indicador pesquisa foi o de aprendizado. Ao serem questionados sobre qual a importância de se aprender algo no atrativo, 35\% dos turistas indicaram muita importância, seguidos de $28,7 \%$ que denotaram máxima importância e 27,9\% média importância. Do total de turistas, apenas $8,4 \%$ indicaram pouca ou nenhuma importância para o indicador. $O$ índice de importância do indicador foi de 3,82, ficando entre os níveis de muita e média importância.

$\mathrm{Na}$ avaliação do nível de aprendizado nos atrativos de Florianópolis, os turistas indicaram que foi mediano em $36,5 \%$ dos casos, bom em $34,9 \%$, excelente em $14,8 \%$ e ruim ou péssimo em 13,8\%. Destaca-se aqui que os índices somados de avaliação média, ruim e péssima somam mais de 50\%, mostrando que há muito a ser feito em relação a este indicador. 
O índice geral de avaliação do indicador de aprendizagem nos atrativos de Florianópolis foi de 3,48, ficando entre o médio e o bom.

Ao realizar-se o teste de comparação dos índices, verificou-se que existe diferença significativa $(\mathrm{t}=5,83$ e $\mathrm{p}=0,000)$ e que os turistas apesar de não considerarem extremamente importante o aprendizado no atrativo, não estão satisfeitos com o que aprenderam no consumo dos mesmos.

O segundo indicador da categoria de experiência é o entretenimento, ou seja, o nível de diversão que o turista tem no consumo do atrativo. Na verificação da importância desse indicador para definição da qualidade de atrativos turísticos, 46,8\% dos respondentes da pesquisa indicaram máxima importância, seguidos de 41,2\% que denotaram muita importância e 8,7\% média importância. Os turistas que responderam que o indicador tem pouca ou nenhuma importância somaram 3,3\%. O índice de importância do indicador foi de 4,1, ficando entre os níveis de muita e máxima importância.

$\mathrm{Na}$ avaliação do indicador, os turistas de Florianópolis responderam que o nível de diversão no consumo dos atrativos foi bom em $44 \%$ dos casos, seguido de excelente em $31,1 \%$, mediano em $19,9 \%$ e ruim ou péssimo em 4,9\%. O índice de avaliação do indicador foi de 4 , considerado bom pelos turistas.

Apesar de ser considerada boa pelos turistas, a avaliação do indicador ainda tem uma distância significante estatisticamente $(t=5,15$ e $\mathrm{p}=0,000)$ para a importância que o mesmo tem para os turistas. Infere-se a partir das análises realizadas até aqui que a gestão da qualidade deste indicador não é prioritária para os atrativos de Florianópolis, pois tem uma boa avaliação e a distância para a importância que tem não é tão grande, apesar de significante.

O terceiro indicador analisado pelos turistas foi a estética. Ao serem questionados sobre a importância do atrativo ser bonito, estar bem disposto e ser agradável ao olhar, $61,1 \%$ dos respondentes mencionou máxima importância, seguidos de 33,8\% que indicaram muita importância. Somente $2,1 \%$ dos turistas responderam que o indicador tem média ou pouca importância e não houve ocorrências de turistas que responderam nenhuma importância. $\mathrm{O}$ índice de importância do indicador foi de 4,62, ficando bem próximo da máxima importância.

$\mathrm{Na}$ avaliação do indicador levando-se em consideração os atrativos de Florianópolis, os turistas indicaram excelente ou boa qualidade na beleza do atrativo em $84,8 \%$ dos casos, média qualidade em $11,5 \%$ e ruim ou péssima qualidade em 3,6\%. O índice de avaliação da beleza dos atrativos da cidade foi de 4,38, superando a boa avaliação e chegando perto da excelência. 
Apesar de ter uma ótima avaliação perante os turistas, na comparação com o nível de importância do indicador, verificou-se que a qualidade real está aquém da importância do indicador na qualidade geral do atrativo denotada pelos turistas $(t=4,99$ e $p=0,000)$. Entretanto, infere-se que, assim como outros indicadores, a estética está bem avaliada pelos turistas que visitaram Florianópolis e não configura-se como indicador prioritário para gerenciamento.

O último indicador da categoria de experiência é a evasão, ou seja o nível que o atrativo faz com que o turista saia da sua rotina normal. Aos serem questionados sobre a importância disso para a qualidade geral do atrativo, 59,4\% dos turistas indicaram máxima importância, seguidos por 34,1\% com muita importância. As respostas de média, pouca e nenhuma importância somaram 6,5\%. O índice de importância deste indicador foi de 4,51.

Ao analisar a avaliação que os turistas fizeram do nível de fuga de rotina nos atrativos de Florianópolis, verificou-se que 53,5\% deles denotaram excelência no indicador, seguido de $33,2 \%$ que o acharam bom e 9,8\% mediano. Ainda 3,5\% dos turistas consideraram ruim a questão da evasão nos atrativos da cidade. $O$ índice de qualidade do indicador de evasão foi de 4,37, ultrapassando o índice de bom e chegando perto da excelência.

Na comparação dos níveis de importância e avaliação real da qualidade no indicador de evasão, apesar dos dois índices terem ultrapassado o nível 4 e estarem relativamente próximos, $o$ teste- $t$ resultou em diferença estatística significante $(t=2,94$ e $p=0,003)$. Entretanto, assim como outros indicadores com o mesmo perfil, a avaliação deste indicador para os atrativos de Florianópolis é considerada satisfatória para os turistas, devendo ter foco secundário nos processos de melhoria.

Após a identificação dos níveis de importância e da avaliação dos indicadores por parte dos turistas de Florianópolis da categoria de experiência foi realizada a comparação geral da mesma. Assim, chegou-se a um nível de importância de 4,31, reforçando a efetividade do modelo teórico utilizado, pois os indicadores que a compõem, na média, resultam em grande importância. Além disso, o nível de qualidade dos indicadores da categoria teve um índice de 4,05, o que também é considerado satisfatório, ultrapassando o índice considerado bom. Como visto na análise específica dos indicadores, a categoria Experiência é considerada importante, tem bons níveis de avaliação na cidade pesquisada. $\mathrm{O}$ teste de comparação da diferença entre importância e avaliação da qualidade na categoria foi significante $(\mathrm{t}=6,87 \mathrm{e} \mathrm{p}=0,000)$, demonstrando que mesmo tendo altos índices de qualidade, ainda está aquém da importância que os turistas dão para os indicadores.

O quadro 2 apresenta o resumo dos resultados. 
Quadro 2 - Resumo dos resultados nos Indicadores

\begin{tabular}{|c|c|c|}
\hline Importância & Indicador & Avaliação \\
\hline 4,62 & Estética & 4,38 \\
\hline 4,51 & Evasão & 4,37 \\
\hline 4,1 & Entretenimento & 4 \\
\hline 3,82 & Aprendizado & 3,48 \\
\hline
\end{tabular}

Fonte: dados primários (2014)

\section{CONSIDERAÇÕES FINAIS}

O turista é parte integrante do processo turístico, ele vivencia emoções e experiências nas suas viagens. Neste processo ele tem a percepção da qualidade do serviço ofertado nos atrativos turísticos. Simultaneamente e intuitivamente, ele avaliará as quatro dimensões da economia da experiência estudadas por Pine e Gilmore para ter sua ideia geral de qualidade.

$\mathrm{Na}$ avaliação do questionário, chegou-se a um nível de importância de 4,31 da categoria de experiência, resultando em uma média geral de grande importância aos índices ligados à experiência. Além disso, o nível de qualidade dos indicadores da categoria teve um índice de 4,05, o que também é considerado satisfatório, ultrapassando o índice considerado bom. Como visto na análise específica dos indicadores, esta categoria é considerada importante, tem bons níveis de avaliação e configura-se como destaque da atividade turística de Florianópolis.

O item que revela maior insatisfação dos turistas pesquisados na categoria é o aprendizado, o que mostra que o turismo cultural merece mais atenção na cidade. O centro e bairros históricos devem ser melhor explorados, seja por parte de profissionais como guias turísticos ou por roteiros autoguiados. O aprendizado do turista pode estar prejudicado pela falta de divulgação das ferramentas de informação existentes. Se faz necessário um estudo específico para avaliar se o aprendizado não está sendo satisfatório pela inexistência das ferramentas ou pela falta de divulgação das existentes.

Outros estudos podem focar seus esforços em fazer relações destes quatro indicadores com outros indicadores da qualidade de serviços. Além disso, realizar estudos de cunho qualitativo, em complementariedade a estudos quantitativos pode ser uma opção válida no quesito do turismo de experiência. 
Apesar de todas as vertentes e perspectivas que existem sobre a experiência no turismo, utilizá-la como ferramenta de marketing se torna relevante, pois proporciona a gestores a melhoria do produto, maior efetividade nas ações de promoção e comercialização, identificação de segmente de mercado, entre outros. Assim, avaliar a qualidade da experiência pode ser considerado o input primário para um ciclo de desenvolvimento da qualidade, satisfação e melhorias em destinos e atrativos, colocando o turista como papel central nas decisões gestoras da área.

\section{REFERÊNCIAS}

Akel, G. M., Gândara, J. M. G., \& Brea, J. A. F. (2012). Métricas da Qualidade da Experiência do Consumidor de Bares e Restaurantes: Uma Revisão Comparada. Revista Rosa dos Ventos, Caxias do Sul (RS), v. 4, n. 3, p. 416-439.

Barbosa, Maria de Lourdes de Azevedo; Farias, Salomão Alencar de. (2012) Em Busca de Uma Experiência Extraordinária em Serviços de Restaurante. Revista Rosa dos Ventos, Caxias do Sul (RS), v. 4, n. 3, p. 440-454.

Beni, M. C. (2004). Turismo: da economia de serviços à economia da experiência. TurismoVisão e Ação, 6(3), 295.

Buhalis, D. (2000). Marketing the competitive destination of the future.Tourism management, 21(1), 97-116.

Collis, J., \& Hussey, R. (2005). Pesquisa em administração: um guia prático para alunos de graduação e pós-graduação. Bookman.

Creswell, J. W., \& Clark, V. L. P. (2007). Designing and conducting mixed methods research.

Cronin Jr, J. J., \& Taylor, S. A. (1992). Measuring service quality: a reexamination and extension. The journal of marketing, 55-68.

Diez, B. S. (1999). HOTELQUAL: Una escala para medir la calidad percibida en servicios de alojamiento. Estudios turísticos, 95-110.

Fecomercio-SC. (2014) Dados do Turismo catarinense: perfil da demanda no Carnaval. Fernández, Juan Ignacio Pulido; Hermoso, Úrsula Navarro. (2014) Identificación de ítems para medir las experiências del turista en destino. Cultur - Revista de Cultura e Turismo, Ilhéus (BA), v. 8, n. 1, p. 4-34.

Frochot, I., \& Hughes, H. (2000). HISTOQUAL: The development of a historic houses assessment scale. Tourism management, 21(2), 157-167.

Gil, A. C. (2002). Como elaborar projetos de pesquisa. São Paulo.

Gimenes, M. H. S., Brea, J. A. F. \& Gândara, J. M. G. (2012). Comidas Inolvidables: la construcción de una metodologia para analizar las experiencias de comer fuera de casa.

$\begin{array}{lllll}\text { Estudios } y & \text { perspectivas } & \text { en }\end{array}$ 
Gomes, A. M., Salazar, V. S., \& Leite, Y. V. P. (2011). Hotelaria de Luxo: como elementos visuais do ambiente estimulam a expectativa das experiências extraordinárias. Turismo e Sociedade, 6(3).

Horodyski, G. S., Manosso, F. C., \& Gândara, J. M. G. (2012). O consumo de souvenirs ea experiência turística em Curitiba (PR). Caderno Virtual de Turismo, 12(3), 323-342.

Hughey, D. W., Chawla, S. K., \& Khan, Z. U. (2003). Measuring the quality of university computer labs using SERVQUAL: a longitudinal study. Quality Management Journal, 10(3).

Hume, M. (2011). How do we keep them coming?: examining museum experiences using a services marketing paradigm. Journal of Nonprofit \& Public Sector Marketing, 23(1), 71-94.

IBGE. Dados econômicos do Brasil. Instituto Brasileira de Pesquisa e Estatística. Disponível em IBGE.gov.br, 2012.

Jayasundara, C. C., Ngulube, P. \& Minishi-Majanja, M. K. (2009). A theoretical model to predict customer satisfaction in relation to service quality in selected university libraries in Sri Lanka.

Knutson, B. J., Stevens, P., \& Patton, M. (1996). DINESERV: Measuring service quality in quick service, casual/theme, and fine dining restaurants.Journal of Hospitality \& Leisure Marketing, 3(2), 35-44.

Kotler, P., \& Keller, K. L. (2006). Administração de marketing.

Ladeira Júnior, W., Santini, F., \& Costa, G. (2013). Antecedentes e Dimensões da Experiência de Consumo: uma abordagem experimental na satisfação de hóspedes. Turismo em Análise, 24(1).

Lovelock, C., \& Wright, L. (2007). Serviços: marketing e gestão. Saraiva.

Malhotra, N. K. (2006). Pesquisa de marketing: uma orientação aplicada. Bookman.

Mattar, F. N. (1996). Pesquisa de marketing-Volume 1: Metodologia e planejamento. São Paulo: Atlas.

Melo, L. D. S. A., Souza, A. G. D., Kovacs, M. H., \& Barbosa, M. D. L. D. A. (2011). Gestão da experiência de serviços de hospitalidade: o que a empresa propõe e qual o significado para o consumidor. Revista Acadêmica Observatório de Inovação do Turismo, (2), 01-a.

Mondo, T. S., \& Costa, J. I. P. D. (2010). Marketing de Experiência para intermediários: possibilidades e limitações do Fam-Tour na hotelaria. Revista Hospitalidade, 7(2), 90-110.

Mondo, Tiago Savi. (2010) Turismo no Rio do Rastro Eco Resort, SC: um relato de experiência. Revista Turismo \& Desenvolvimento, 9 (2).

Mondo, Tiago Savi. (2014) Tourqual: Proposal of a model for evaluating the quality of services in tourism attractions. Thesis (Doctor in Administration) Center of Social and 
Economics Sciences - CSE, Federal University of Santa Catarina State, UFSC, Santa Catarina State, SC, Brazil.

Nascimento, I., Maia, A. F., \& Dias, P. O. D. O. (2013). A experiência como produto turístico: a emoção ea sensação do novo e diferente. revista turismo: estudos e práticas, 1(2).

Organização Mundial do Turismo [OMT]. (2012) Dados econômicos do Turismo. Recuperado em 10 de novembro, 2011, de http://www2.unwto.org/en.

ONU. (1994) Workshop on sustainable tourism development in countries in transition. Committee on human settlements, 23 february.

ONU. (1999) Tourism and sustainable development. Commission on Sustainable Development 19-30 April.

Parasuraman, A., Zeithaml, V. A., \& Berry, L. L. (1985). A conceptual model of service quality and its implications for future research. the Journal of Marketing, 41-50.

Parasuraman, A., Zeithaml, V. A., \& Berry, L. L. (1988). Refinement and reassessment of the SERVQUAL scale. Journal of Retailing . 67, n. 4, Winter,1991. p. 420-450

Parasuraman, A., Zeithaml, V., \& Berry, L. (2002). SERVQUAL: a multiple-item scale for measuring consumer perceptions of service quality. Retailing: critical concepts, 64(1), 140.

Pine, B. J., \& Gilmore, J. H. (1998). Welcome to the experience economy.Harvard business review, 76, 97-105.

Pine, B. J., \& Gilmore, J. H. (1999). The experience economy: work is theatre \& every business a stage. Harvard Business Press.

Pulido-Fernández, J. I. \& Hermoso, Ú. N. (2014). Identificación de ítems para medir las experiencias del turista en destino. CULTUR-Revista de Cultura e Turismo, 8(1), 04-34.

Santos, G. E. D. O., \& Silva, P. G. (2011). A qualidade da experiência dos visitantes ao Museu do Futebol. Revista Acadêmica Observatório de Inovação do Turismo, (2), 02-a.

Santur-Santa Catarina Turismo, S. A. (2013) Pesquisa mercadológica estudo da demanda turística. Sinopse comparativa.

Sierra Díez, B. et. al. (1999). HOTELQUAL: Una escala para medir la calidad percibida en servicios de alojamiento. Estudios turísticos, (139), 95-110.

Teas, R. K. (1994). Expectations as a comparison standard in measuring service quality: an assessment of a reassessment. The journal of marketing, 132-139.

Tonini, H., \& Lavandoski, J. (2011). Enoturismo: experiências e sensações no Vale dos Vinhedos (RS). Revista Turismo em Análise, 22(1), 25-43.

Tuan, Y. F. (1980). Topofilia. São Paulo: Difel. 